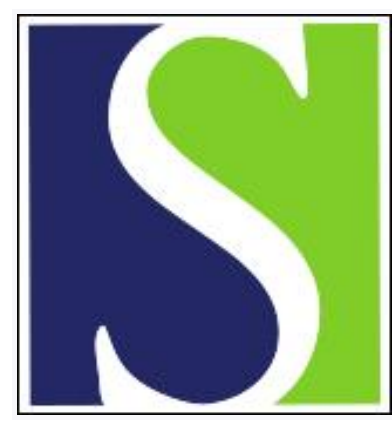

Scand J Work Environ Health 2002;28(3):158-162

https://doi.org/10.5271/sjweh.659

Issue date: Jun 2002

Self-experienced physical workload and risk of breast cancer

by Rintala PE, Pukkala E, Paakkulainen HT, Vihko VJ

Affiliation: LIKES Research Center, Rautpohjankatu 10, FI-40700 Jyväskylä, Finland. Pirjo.Rintala@likes.fi

The following article refers to this text: 2008;34(1):73-79

Key terms: breast cancer; malignant tumor; occupational physical activity; physical workload; risk; self-assessment; self-experienced physical workload; self-report; woman

This article in PubMed: www.ncbi.nlm.nih.gov/pubmed/12109554 


\title{
Self-experienced physical workload and risk of breast cancer
}

\author{
by Pirjo E Rintala, MD,' Eero Pukkala, PhD, ${ }^{2}$ Harri T Paakkulainen, MSc, ${ }^{3}$ Veikko J Vihko, PhD ${ }^{1}$
}

\begin{abstract}
Rintala PE, Pukkala E, Paakkulainen HT, Vihko VJ. Self-experienced physical workload and risk of breast cancer. Scand J Work Environ Health 2002;28(3):158-162.

Objectives The association between the risk of breast cancer and the physical load of work was studied because physical activity may reduce breast cancer risk via hormonal mechanisms.

Methods Occupational physical activity was estimated from a self-determined rating [scale 1 (low) -5 (high)] of occupational physical load for 1800 randomly selected women born in 1930-1969. The medians of the ratings were used as occupation-specific indices of occupational physical activity. All 65 occupations with at least 5 ratings, covering $75 \%$ of the economically active female population in Finland, were included in further analyses. The occupation-specific numbers of observed and expected cases of breast cancer during 1971-1995 among women born in 1906-1945 (17986 cases) were grouped according to the index for occupational physical activity. Expected rates were calculated with the social-class-specific population and the entire Finnish female population as reference populations. The relative risks (RR) of breast cancer for categories 3-5, in comparison with categories 1-2 were calculated using Poisson regression models. The occupation-specific mean number of children and mean age at first childbirth were adjusted for.

Results The RR was lower for occupations in category 5 than for those in categories 1-4, especially in the youngest (25-39 years) age group (RR 0.51, 95\% confidence interval 0.44-0.58). Adjustment for social class and reproductive factors raised the RR (95\% confidence interval $0.56-0.74)$ for category 5 in different age strata, all the RR values still being statistically significant.

Conclusions The results support the hypothesis that occupational physical activity, if high enough, markedly reduces breast cancer risk.
\end{abstract}

Key terms malignant tumor, occupational physical activity, women.

An increasing number of epidemiologic studies has reported an inverse association between the risk of breast cancer and recreational or occupational physical activity. [For reviews, see references 1-3.] Studies on occupational physical activity in the United States, Europe, and Asia have, in most cases, found a slightly decreased risk of breast cancer in physically straining occupations (4-11). However, there are also studies that have shown no association $(12,13)$ or have even shown an increased risk (14).

The objective of this study was to obtain an estimate of breast cancer incidence in association with self-rated occupational physical activity among the economically active female population of Finland. We created a fiveclass index for the physical load of the most common
Finnish occupations and linked it to the occupation-specific incidence of breast cancer during 1971-1995, with adjustment for age, social class, and two reproductive factors.

\section{Material and methods}

In the 1970 population census of Finland, an occupation was defined as the major activity performed towards earning an income. The job titles, provided by every Finnish citizen in the self-administered questionnaire of the census, were converted into threedigit job codes according to the Nordic Classification

1 LIKES (Foundation for Promotion of Sport and Health Sciences) Research Center, Jyväskylä, Finland.

2 Finnish Cancer Registry, Institute for Epidemiological and Statistical Cancer Research Helsinki, Finland.

3 Institute of Occupational Health, Helsinki, Finland.

Reprint requests to: Dr Pirjo Rintala, LIKES Research Center, Rautpohjankatu 10, FIN-40700 Jyväskylä, Finland. [E-mail: Pirjo.Rintala@likes.fi] 
of Occupations and the International Classification of Occupations (15). These codes were added to the files of the Finnish Cancer Registry for every cancer patient born in 1906-1945 with a cancer diagnosed in 19711995 through record linkage based on the personal identification numbers of Finnish citizens.

In order to create an index for occupational physical activity, we randomly selected 1800 Finnish women, born in 1930-1969, and asked them to name their occupation in a structured postal questionnaire in 1994 and, further, to rate the physical load of their occupations with scores of $1-5$. Class 1 consisted of jobs involving sitting and the performance of light tasks with the hands only. Class 2 involved the handling of heavier items, such as in work along industrial conveyor belts. Class 3 involved bodily motion such as in light work incorporating walking and standing. Professions in this class included, for example, teachers, pharmacists, hairdressers, and shopkeepers. Class 4 involved walking upstairs or long distances, bending from the waist, and carrying, in other words, all activities that use the major muscle groups of the body and notably increase energy consumption. Professions in this class included nursing, warehouse work, and cleaning. Class 5 differed from class 4 in that heavy tasks were performed for most of the workday, for example, the tasks performed by farmers and livestock workers. In addition to the women's "current" occupation, their occupations "at 20 years of age" and "at 35 years of age" were also similarly requested. The medians of the load ratings for each occupation served as the job-title-specific physical activity. The "current" occupation, as stated by the subjects, was included in the classification. Only occupations with at least five ratings were accepted. These occupations covered $76 \%$ of the economically active female population in Finland in 1985 (ie, 680000 women or over 16 million person-years at follow-up) (16). The number of the breast cancer cases was 17986 . The $24 \%$ of the Finnish women in excluded occupations had 5721 cases of breast cancer (ie, $24 \%$ of all breast cancer cases in this age range).

For each of the 65 job titles with occupational physical activity, the observed number of breast cancer cases for each job title during 1971-1995 was subdivided into eight 5-year and birth-year categories between 1906-1945, five 5-year calendar periods, and four social classes (17). Expected numbers were counted separately for each stratum according to the following two alternative reference populations: (i) the entire economically active female population and (ii) women of the social class to which the subjects belonged. The four social classes were defined as follows: (i) managers and other higher administrative or clerical employees, farmers owning more than 50 hectares of land, (ii) lower administrative or clerical employees, small-scale entrepre- neurs, farmers owning 15 to 49.9 hectares of land, (iii) skilled and specialized workers, farmers owning 5 to 14.9 hectares of land, (iv) laborers, farm and forestry workers, institutions' inmates, farmers owning less than 5 hectares of land, pensioners whose former occupations were unknown (18). Job-title-specific standardized incidence ratios were calculated as intermediary statistics adjusting for year of birth and calendar period, and, for the social-class-adjusted SIR values, also for social class.

Poisson regression models (19) were used for assessing the adjusted ratios of observed to expected cases, which were interpreted as the relative risks for different occupational physical activities. A combined class containing the greatly similar scores of 1 and 2 was used as the reference class. The number of observed cases (response variable) and the number of expected cases (offset) were incorporated into the multiplicative Poisson regression model. It would have been possible to base the model also on observed cases and person-years, but it would have forced us to calculate the age estimates from the data and would have led to a loss of degrees of freedom and broader confidence intervals. Therefore the method based on observed and expected cases has been frequently used in analyses in which age relations are essential (and for which a calculation of expected rates is possible). The occupation-specific average number of children among Finnish women 40-45 years of age in 1985 and the respective mean age at first childbirth were included in the analysis (17). Some earlier studies have reported that there is a greater decrease in the risk of breast cancer with increasing levels of occupational physical activity among premenopausal than postmenopausal women or that protection was only observed during the premenopausal period $(5,8-10)$. On the basis of these findings, the subjects were grouped as clearly of premenopausal age (25-39 years of age at the beginning of each 5-year calendar period), of postmenopausal age ( $\geq 55$ years of age), and of intermediate age (40-54 years of age). All the calculations were made using the SAS 6.12 computer statistics software package (20).

\section{Results}

In our cohort, 17986 breast cancer cases were found by the Finnish Cancer Registry. The cases were rather evenly distributed through the various classes of occupational physical activity. The age-specific standardized incidence ratios varied from 1.05 to 1.16 for the lightest occupations and from 0.77 to 0.80 for the heaviest occupations (table 1). Adjustment for social class and reproductive factors diminished the variation between 
Table 1. Observed and expected numbers of breast cancer cases and the standardized incidence ratios (SIR) with 95\% confidence intervals $(95 \% \mathrm{CI})$ for breast cancer at different levels of occupational physical activity as classes $1-5$ a . Reference: entire female population adjusted for age, period, and social class.

\begin{tabular}{lcccc}
\hline $\begin{array}{l}\text { Age at } \\
\text { follow up }{ }^{b}\end{array}$ & $\begin{array}{c}\text { Observed } \\
(\mathrm{N})\end{array}$ & $\begin{array}{c}\text { Expected } \\
(\mathrm{N})\end{array}$ & SIR & $95 \% \mathrm{Cl}$ \\
\hline $\begin{array}{c}\text { 25-39 years } \\
\text { Class 1+2 }\end{array}$ & 374 & 323 & 1.16 & $1.04-1.28$ \\
Class 3 & 304 & 259 & 1.17 & $1.05-1.31$ \\
Class 4 & 585 & 554 & 1.06 & $0.97-1.14$ \\
Class 5 & 431 & 562 & 0.77 & $0.70-0.84$ \\
40-54 years & & & & \\
Class 1+2 & 1371 & 1222 & 1.12 & $1.06-1.18$ \\
Class 3 & 1033 & 930 & 1.11 & $1.04-1.18$ \\
Class 4 & 1832 & 1763 & 1.04 & $0.99-1.09$ \\
Class 5 & 1255 & 1568 & 0.80 & $0.76-0.85$ \\
$\geq 55$ years & & & & \\
Class 1+2 & 3430 & 3254 & 1.05 & $1.02-1.09$ \\
Class 3 & 2401 & 2303 & 1.04 & $1.00-1.09$ \\
Class 4 & 3543 & 3357 & 1.06 & $1.02-1.09$ \\
Class 5 & 1427 & 1824 & 0.78 & $0.74-0.82$ \\
All ages & & & & \\
Class 1+2 & 5175 & 4799 & 1.08 & $1.05-1.11$ \\
Class 3 & 3738 & 3491 & 1.07 & $1.04-1.11$ \\
Class 4 & 5960 & 5675 & 1.05 & $1.02-1.08$ \\
Class 5 & 3113 & 3954 & 0.79 & $0.76-0.82$ \\
\hline
\end{tabular}

a Class $1=$ jobs involving sitting and light tasks with the hands only, class $2=$ handling of heavier items (eg, work along industrial conveyor belts), class $3=$ jobs involving bodily motion (eg, in light work incorporating walking and standing), class $4=$ jobs involving walking upstairs or long distances, bending from the waist, and carrying (ie, all activities using major muscle groups and notably increasing energy consumption, class 5 = same as class 4 except that heavy tasks were performed for most of the workday.

$\checkmark$ At the beginning of each 5 -year period.

the classes. When both were added to the model, the rate ratio remained remarkably low only for class 5 when compared with the classes 1 and 2 combined (table 2). The relationship between occupational physical activity and rate ratio was strongest in the youngest age group, the rate ratio for class 5 being 0.68 (95\% CI 0.51-0.93).

\section{Discussion}

Currently, we know of 12 studies on the association between breast cancer and occupational physical activity. Nine of these studies are retrospective or prospective cohort studies $(4-7,9,11,12,14,21)$, and three are population- or hospital-based case-referent studies $(8,10$, 13). Job titles $(4,5,10,21)$, subjects' self-ratings of activity level at work $(7-9,12)$, estimated time spent in a sitting position during workhours $(6,13)$, index of weekly energy expenditure (11), and index based on hours at each level of activity during a day as weighted by relative oxygen consumption (14) have been used as the basis for classifying the occupational physical activities. Most of these studies have suggested a decreased risk of breast cancer in physically demanding occupations. The greatest reported risk reduction was $52 \%$ in the study by Thune et al (9) with control for age at entry, county of residence, number of children, age at birth of first child, intake of total fat and energy, and body mass index (9).

In our study the risk decrease of the physically most active occupation was about $30 \%$ when adjusted for social class or reproductive factors, but only some $20 \%$ if adjusted for both of these factors. It is evident that the main factor shown as social class variation in breast cancer incidence is actually social class variation in reproductive factors (17). Therefore, adjustment for both social class and reproductive factors in the same model probably leads to overadjustment. Thus the standardized incidence ratios adjusted for social class only may be closer to the truth.

Our results showed a decreased risk of breast cancer for physically heavy occupations in Finland, and they are therefore in agreement with the majority of findings from earlier studies. Due to the nondifferential misclassification error, the variation between the categories used for occupational physical activity was smaller when classified by group averages than it would have been if the index for occupational physical activity could have been used for each person (ie, the true protective effect of physically intense work is likely to be more than that observed in this study setting). In class 5 ("heavy physical work"), workload was perceived very similarly by the subjects. All the subjects rated their workload with scores of 4 or 5 . In some other occupations, such as nursing, the rating distributions were broad due to the variation in their status in hierarchy (chief nurse or ward nurse, etc) and worksite (emergency unit, chronic ward, operating theater, hospital administration, etc).

However, when our analysis was restricted to the most homogeneous occupations with $80 \%$ occupational physical activity scores of \pm 1 class around the median (31 occupations, 11139 breast cancer cases), the trend of decreasing risk by increasing workload did not materially change (table 2). Not only can the between-worker variability in occupational physical activity differ from week to week, but subjective intrapersonal reporting can also, and thus cause misclassification.

The ratings of the women born in 1930-1969 were applied to the women working in the 1970s. This use was considered justified. Although the absolute heaviness of work may have diminished, the ranking of occupational physical activity can be assumed to be rather stable. In our analysis the occupation-specific average numbers of children and mean ages at first birth in 1985 were used to adjust for reproductive factors instead of having had these data available on an individual level. Since residual confounding is possible among women 
Table 2. Relative risk (RR) of breast cancer and the $95 \%$ confidence intervals $(95 \% \mathrm{Cl})$ for occupations according to the index for occupational physical activity as classes $1-5^{\text {a }}$ and age group, derived from models with different exclusions and adjustments.

\begin{tabular}{|c|c|c|c|c|c|c|}
\hline \multirow{3}{*}{$\begin{array}{l}\text { Occupations } \\
\text { according to } \\
\text { adjustment }\end{array}$} & \multicolumn{6}{|c|}{ Age group } \\
\hline & \multicolumn{2}{|c|}{$25-39$ years } & \multicolumn{2}{|c|}{$40-54$ years } & \multicolumn{2}{|c|}{$\geq 55$ years } \\
\hline & $\mathrm{RR}$ & $95 \% \mathrm{Cl}$ & $\mathrm{RR}$ & $95 \% \mathrm{Cl}$ & $\mathrm{RR}$ & $95 \% \mathrm{Cl}$ \\
\hline \multicolumn{7}{|c|}{ All occupations, unadjusted } \\
\hline Class $1+2$ & \multicolumn{2}{|c|}{1.0 (reference) } & \multicolumn{2}{|c|}{1.0 (reference) } & \multicolumn{2}{|c|}{1.0 (reference) } \\
\hline Class 3 & 0.92 & $0.79-1.07$ & 0.87 & $0.80-0.94$ & 0.90 & $0.86-0.95$ \\
\hline Class 4 & 0.68 & $0.64-0.74$ & 0.69 & $0.64-0.74$ & 0.82 & $0.78-0.86$ \\
\hline Class 5 & 0.51 & $0.44-0.58$ & 0.55 & $0.51-0.59$ & 0.61 & $0.57-0.65$ \\
\hline \multicolumn{7}{|c|}{ All occupations, adjusted for social class only } \\
\hline Class $1+2$ & \multicolumn{2}{|c|}{1.0 (reference) } & \multicolumn{2}{|c|}{1.0 (reference) } & \multicolumn{2}{|c|}{1.0 (reference) } \\
\hline Class 3 & 1.01 & $0.87-1.18$ & 0.99 & $0.91-1.07$ & 0.99 & $0.94-1.04$ \\
\hline Class 4 & 0.91 & $0.80-1.04$ & 0.93 & $0.86-0.99$ & 1.00 & $0.95-1.05$ \\
\hline Class 5 & 0.66 & $0.58-0.76$ & 0.71 & $0.66-0.77$ & 0.74 & $0.70-0.79$ \\
\hline \multicolumn{7}{|c|}{$\begin{array}{l}\text { All occupations, adjusted for reproductive } \\
\text { factors only }\end{array}$} \\
\hline Class $1+2$ & \multicolumn{2}{|c|}{1.0 (reference) } & \multicolumn{2}{|c|}{1.0 (reference) } & \multicolumn{2}{|c|}{1.0 (reference) } \\
\hline Class 3 & 0.97 & $0.83-1.14$ & 0.96 & $0.87-1.05$ & 0.96 & $0.91-1.02$ \\
\hline Class 4 & 0.74 & $0.62-0.88$ & 0.81 & $0.74-0.89$ & 0.89 & $0.84-0.95$ \\
\hline Class 5 & 0.56 & $0.41-0.76$ & 0.71 & $0.59-0.85$ & 0.71 & $0.59-0.85$ \\
\hline \multicolumn{7}{|c|}{$\begin{array}{l}\text { All occupations, adjusted for both social class } \\
\text { and reproductive factors }\end{array}$} \\
\hline Class $1+2$ & \multicolumn{2}{|c|}{1.0 (reference) } & \multicolumn{2}{|c|}{1.0 (reference) } & \multicolumn{2}{|c|}{1.0 (reference) } \\
\hline Class 3 & 0.99 & $0.85-1.17$ & 1.02 & $0.94-1.11$ & 1.01 & $0.96-1.07$ \\
\hline Class 4 & 0.90 & $0.76-1.07$ & 0.99 & $0.91-1.09$ & 1.04 & $0.98-1.11$ \\
\hline Class $5^{b}$ & 0.68 & $0.51-0.93$ & 0.84 & $0.70-1.00$ & 0.82 & $0.71-0.94$ \\
\hline Class $5^{c}$ & 0.58 & $0.45-0.69$ & 0.77 & $0.67-0.87$ & 0.87 & $0.77-0.98$ \\
\hline \multicolumn{7}{|c|}{$\begin{array}{l}\text { Only occupations with homogeneous physical } \\
\text { load d, unadjusted }\end{array}$} \\
\hline Class $1+2$ & \multicolumn{2}{|c|}{$1.0($ reference $)$} & \multicolumn{2}{|c|}{1.0 (reference) } & \multicolumn{2}{|c|}{1.0 (reference) } \\
\hline Class 3 & 0.94 & $0.76-1.15$ & 0.92 & $0.81-1.03$ & 0.84 & $0.77-0.90$ \\
\hline Class 4 & 0.64 & $0.52-0.78$ & 0.73 & $0.66-0.82$ & 0.77 & $0.71-0.83$ \\
\hline Class 5 & 0.52 & $0.42-0.63$ & 0.61 & $0.54-0.69$ & 0.62 & $0.57-0.67$ \\
\hline
\end{tabular}

differing from the average, we studied the effect of excluding an occupation, agricultural workers, with exceptionally large variation in this respect. Agricultural workers are known to have considerably more children, on the average, than the general Finnish population and also a markedly low incidence of breast cancer (22). Agricultural work is the predominant occupation in class 5 (16\% of all class 5 occupations). Excluding them did not change the result (table 2). Thus the low risk of breast cancer in occupational physical activity class 5 was not attributable to agricultural work.

Endocrinologic mechanisms are crucial to the development of breast cancer. High levels of estrogens and progesterone play a central role in exposing breast tissue to harmful effects. Their serum levels are known to decrease with exercise (23), even with exercise of moderate intensity (24-26), under experimental conditions.
Whether this mechanism holds true for occupational physical activity is not known, although moderate levels of physical activity, as found among cleaners, kitchen staff, and clerical workers at hospitals, appear to affect the female reproductive system, as measured by the time to pregnancy (ie, fecundability) (27). Leisure-time physical activity is not related to menopausal age (28). We are not aware of any studies on the age at menopause and occupation or on sex-steroid serum hormone levels and occupation. It is assumed that physical activity exerts its protective effect on breast cancer risk through ovarian function via changes in menstrual characteristics; certain time period(s) in a woman's life, such as preadolescence, adolescence and menopause, may be of special importance. In the case of occupational physical activity, effects on early menstrual events are canceled out in today's Finland. 
So far, it is not known what property or dimension of physical activity may be related to the risk of breast cancer. Some studies on recreational physical activity and breast cancer $(1,29,30)$ have shown the risk to decrease with an increasing intensity of leisure-time physical activity. In this study the protective effect of occupational physical activity after all adjustments increased towards the heaviest class of occupational physical activity. This finding highlights the importance of exercise intensity.

\section{Acknowledgments}

This study has been financially supported by the Ministry of Education, Helsinki, Finland, and the Foundation for Promotion of Sport and Health Sciences (LIKES), Jyväskylä, Finland.

\section{References}

1. Friedenreich CM, Rohan TE. Physical activity and risk of breast cancer. Eur J Cancer Prev 1995;4:145-51.

2. Gammon MD, John EM, Britton JA. Recreational and occupational physical activities and risk of breast cancer. J Natl Cancer Inst 1998;90:100-17.

3. Latikka P, Pukkala E, Vihko V. Relationship between the risk of breast cancer and physical activity: an epidemiological perspective. Sports Med 1998;26:133-43.

4. Vena JE, Graham S, Zielezny M, Brasure J, Swanson M. Occupational exercise and risk of cancer. Am J Clin Nutr 1987;45:318-27.

5. Vihko VJ, Apter DL, Pukkala EI, Oinonen M, Hakulinen TR, Vihko RK. Risk of breast cancer among female teachers of physical education and languages. Acta Oncol 1992;31:201-4.

6. Zheng W, Shu XO, McLaughlin JK, Chow W-H, Gao YT, Blot WJ. Occupational physical activity and the incidence of cancer of the breast, corpus uteri, and ovary in Shanghai. Cancer 1993;71:3620-24.

7. Steenland K, Nowlin S, Palu S. Cancer incidence in the National Health and Nutrition Survey I: follow-up data: diabetes, cholesterol, pulse and physical activity. Cancer Epidemiol Biomarkers Prev 1995;4:807-11.

8. D’Avanzo B, Nanni O, La Vecchia C, Franceschi S, Negri E, Giacosa A, et al. Physical activity and breast cancer risk. Cancer Epidemiol Biomarkers Prev 1996;5:155-60.

9. Thune I, Brenn T, Lund E, Gaard M. Physical activity and the risk of breast cancer. N Engl J Med 1997;336:1269-75.

10. Coogan PF, Newcomb PA, Clapp RW, Trentham-Dietz A, Baron JA, Longnecker MP. Physical activity in usual occupation and risk of breast cancer (United States). Cancer Causes Control 1997;8:626-31.

11. Sesso HD, Paffenbarger RS Jr, Lee I-M. Physical activity and breast cancer risk in the College Alumni Health Study (United States). Cancer Causes Control 1998;9:433-39.

12. Albanes D, Blair A, Taylor PR. Physical activity and risk of cancer in the NHANES I population. Am J Public Health 1989;79:744-50.

13. Dosemeci M, Hayes RB, Vetter R, Hoover RN, Tucker M, Engin $\mathrm{K}$, et al. Occupational physical activity, socioeconomic status, and risks of 15 cancer sites in Turkey. Cancer Causes Control 993;4:313-21.

14. Dorgan JF, Brown C, Barret M, Splansky GL, Kreger BE, Agostino RB, et al. Physical activity and risk of breast cancer in the Framingham heart study. Am J Epidemiol 1994; 139:662-9.

15. Central Statistical Office of Finland. Population census 1970: occupation and social position. Helsinki: Central Statistical Office of Finland, 1974. Official statistics of Finland 6C:104, vol 9, 1974.

16. Statistics Finland. Changes in the labour force: population census 1990; vol 2. Helsinki: Statistics Finland, 1993.

17. Pukkala E. Cancer risk by social class and occupation: a survey of 109000 cancer cases among Finns of working age. Basel: Karger, 1995. Contributions to epidemiology and biostatistics, vol 7.

18. Rauhala, U. Social structures of the Finnish society. Helsinki: Ministry of Social Affairs and Health, 1996. Social review 6.

19. Breslow NE, Day NE. Statistical methods in cancer research; vol II (The design and analysis of cohort studies). Lyon: International Agency for Research on Cancer (IARC), 1987. IARC scientific publications, no 82.

20. SAS Institute Inc. SAS/STAT $\odot$ Software: changes and enhancements through release 6.11, Cary (NC): SAS Institute Inc, 1996.

21. Pukkala E, Poskiparta M, Apter D, Vihko V. Life-long physical activity and cancer risk among Finnish female teachers. Eur J Cancer Prev 1993;2:369-76.

22. Pukkala E, Notkola V. Cancer incidence among Finnish farmers, 1979-93. Cancer Causes Control 1997;8:25-33.

23. Arena B, Maffuli N, Maffuli F, Morleo MA. Reproductive hormones and menstrual changes with exercise in female athletes. Sports Med 1995;19:278-87.

24. Ellison PT, Lager C. Moderate recreational running is associated with lowered salivary progesterone profiles in women. Am J Obstet Gynecol 1986;143:1000-3.

25. Bernstein L, Ross RK, Lobo R A, Hanish R, Krailo MD, Henderson BE. The effects of moderate physical activity on menstrual cycle patterns in adolescence: implications for breast cancer prevention. Br J Cancer 1987;55:681-5.

26. Broocks A, Pirke KM, Schweiger U, Tuschl RJ, Laessle RG, Strowitzki T, et al. Cyclic ovarian function in recreational athletes. J Appl Physiol 1990;68:2083-6.

27. Florack EI, Zielhuis GA, Rolland R. The influence of occupational physical activity on the menstrual cycle and fecundability. Epidemiology 1994;5:14-8.

28. Bromberger JT, Matthews KS, Kuller LH, Wing RR, Meilahn EN, Platinga P. Prospective study of the determinants of age at menopause. Am J Epidemiol 1997;145:124-33.

29. Mittendorf R, Longnecker MP, Newcomb PA, Dietz AT, Greenberg R, Bogdan GF, et al. Strenuous physical activity in young adulthood and risk of breast cancer (United States). Cancer Causes Control 1995;6:347-53.

30. McTiernan A, Stanford JL, Weiss NS, Daling JL, Voigt LF. Occurrence of breast cancer in relation to recreational exercise in women age 50-64 years. Epidemiology 1996;7:598604.

Received for publication: 21 January 2000 